\title{
Analisis Hubungan Ketuban Pecah Dini (KPD) dan Paritas dengan Partus Lama
}

\author{
Analysis of The Relationship of Early From Amount and Parity with Old \\ Partusions
}

\section{Yunida Haryanti ${ }^{1}$}

${ }^{1}$ Prodi DIII Kebidanan STIKes Kapuas Raya Sintang, Kalimantan Barat, Indonesia

*Korespondensi penulis: haryantiyunia@gmail.com

Penyerahan: 14-08-2020, Perbaikan: 11-09-2020, Diterima: 26-09-2020

\begin{abstract}
Data obtained from the Regional General Hospital (RSUD) Ade Mohammad Djoen Sintang during the last 3 years there has been an increase in cases of prolonged labor. In 2017 there were 41 cases and in 2018 it increased to 65 cases. And in 2019 there were 47 cases. The causes of prolonged labor at the Ade Mohammad Djoen Sintang Regional General Hospital (RSUD) include uterine inertia, incoordinate uterine action, CPD (Cephalopelvik), fetal position abnormalities (latitude and breech location) (Profile of Ade Mohammad Djoen Hospital, 2019). To find out the analysis of the relationship between premature rupture of membranes (PROM) and parity with prolonged labor in the Ade Mohammad Djoen Regional General Hospital, Sintang District in 2020. The design in this study used a quantitative descriptive research design with a retrospective approach. The population in this study were all mothers who gave birth at the Ade Muhammad Djoen Sintang Regional Hospital in 2019, totaling 1,383 people, the number of samples was 310. The sampling technique used in this study was simple random sampling. The research sample used a checklist sheet. Data analysis used univariate and bivariate analysis. There is a significant relationship, namely the PROM variable $(O R=2.802$; $95 \% C I=2.511-3.295 ; P=0.004)$, this means that mothers who have PROM have a 2.802 times greater chance of experiencing prolonged labor compared to mothers who do not experience prolonged labor. and there is a significant relationship, namely the parity variable $O R=2.891,95 \% C I=3.568-5.237 ; P=0.004)$. This means, mothers who have parity at risk have a 2.891 times greater chance of experiencing prolonged labor than mothers who do not experience prolonged labor. It is hoped that health workers will continue to maintain existing services and even improve them. The services that must be improved are the provision of health education to mothers who give birth about prolonged labor and the consequences of prolonged labor for babies and mothers.
\end{abstract}

Keywords: PROM, Parity, Prolonged labor.

\section{ABSTRAK}

Data yang diperoleh dari Rumah Sakit Umum Daerah (RSUD) Ade Mohammad Djoen Sintang selama 3 tahun terakhir terjadi peningkatan kasus partus lama. Pada tahun 2017 sebanya 41 kasus dan pada tahun 2018 meningkat menjad 65 kasus. Dan pada than 2019 sebnyak 47 kasus. Penyebab partus lama di Rumah Sakit Umum Daerah (RSUD) Ade Mohammad Djoen Sintang diantaranya adalah inersia uteri, incoordinate uterin action, CPD (Cephalopelvik), kelainan letak janin (letak lintang dan sungsang) (Profil RSUD Ade Mohammad Djoen, 2019). Untuk mengetahui Analisis hubungan ketuban pecah dini (KPD) dan paritas dengan partus lama di rumah sakit umum daerah Ade mohammad djoen kabupaten sintang Tahun 2020. Desain pada penelitian ini 
menggunakan desain penelitian deskriptif kuantitatif dengan pendekatan retrospektif. Populasi dalam penelitian ini adalah seluruh ibu yang melahirkan di RSUD Ade Muhammad Djoen Sintang Tahun 2019 yang berjumlah 1.383 orang, jumlah sampel yaitu sebanyak 310 . Teknik pengambilan sampel yang digunakan dalam penelitian ini adalah simple random sampling. Sampel penelitian menggunakan Lembar Ceklist. Analisis data menggunakan analisis Univariat dan bivariat. Adanya hubungan yang signifikan yaitu variabel $\mathrm{KPD}(\mathrm{OR}=2.8 ; 95 \% \mathrm{CI}=2.5-3.3 ; \mathrm{P}=0.004)$, Hal ini berarti ibu yang mngalami KPD mempunyai peluang 2.802 kali lebih besar untuk mengalami partus lama dibandingkan dengan ibu yang tidak mengalami partus lama dan adanya hubungan yang signifikan yaitu variabel paritas $\mathrm{OR}=2.9 ; 95 \% \mathrm{CI}=3.6-5.2 ; \mathrm{P}=0.004)$. Hal ini berarti, ibu yang memunyai paritas berisiko mempunyai peluang 2,891 kali lebih besar untuk mengalami partus lama dibandingkan dengan ibu yang tidak mengalami partus lama. diharapkan kepada petugas kesehatan tetap mempertahankan pelayanan yang sudah ada dan bahkan lebih ditingkatkan lagi. Adapun pelayanan yang harus ditingkatkan adalah pemberian pendidikan kesehatan kepada ibu bersalin tentang partus lama dan akibat dari partus lama pada bayi dan ibu.

Kata kunci: KPD, paritas, partus lama.

\section{PENDAHULUAN}

Persalinan lama merupakan persalinan yang berlangsung lebih dari 18 jam untuk ibu multigravida dimulai dengan tanda-tanda persalinan (Ardhiyanti, 2016). Komplikasi obstetric sangat berpengaruh untuk angka kematian ibu (AKI) diantaranya partus lama. Partus lama rata-rata di dunia menyebabkan kematian ibu sebesar $8 \%$ dan di Indonesia sebesar $9 \%$. Kematian maternal banyak terjadi pada saat persalinan, salah satunya adalah kala II lama (37\%) dan kematian perinatal sendiri salah satu penyebabnya adalah asfiksia pada bayi $(28 \%)$. Partus lama merupakan salah satu penyebab kematian ibu dikarenakan partus lama menyebabkan sepsis, lemas, dehidrasi pada ibu, dapat terjadi perdarahan pasca partum yang sangat membahayakan nyawa ibu (Purnamasari, 2012).

Hampir semua kematian terjadi di negara berpenghasilan rendah dan menengah (99 \%). Mengurangi angka kematian ibu sangat tergantung bahwa perempuan memiliki akses ke perawatan berkualitas sebelum, selama dan setelah melahirkan. Data yang tersedia sejak 2007 menunjukkan bahwa kurang dari setengah dari semua kelahiran di beberapa negara berpenghasilan rendah dan menengah dibantu oleh tenaga kesehatan terlatih. Secara global diperkirakan bahwa lebih dari $40 \%$ semua wanita hamil tidak menerima perawatan antenatal dini di tahun 2013 (WHO 2018).

Survei Demografi kesehatan Indonesia tahun 2017, AKB adalah 24 per 1.000 kelahiran hidup, Penyebab angka kematian bayi (AKB) antara lain, karena infeksi akfiksia neonatorum, trauma kelahiran, cacat bawaan dan prematuritas. $\quad 60 \%$ penyebab kejadian prematur adalah faktor ibu sebagaian besar karena paritas yang tinggi dengan jumlah kejadian di Indonesia sebesar 15,5 per 100 kelahiran hidup atau dengan 675.700 kejadian (SDKI 2017). Data Dinas Kesehatan (Dinkes) Provinsi Kalbar tahun lalu jumlah AKI sebanyak 113 ibu meninggal. Angka 
tersebut makin meningkat sejak Tahun 2018 yang hanya 86 kasus kematian ibu tapi yang sudah masuk tahun 2019 terdapat 113 kasus. jika dikonversi sama dengan 127 per 100.000 kelahiran hidup Namun angka tersebut masih di bawah angka nasional dengan target 306 per 100. 000 kelahiran hidup (Tribunnews, 2020).

Partus lama atau persalinan kasep adalah masalah besar di Indonesia karena pertolongan di daerah pedesaan masih dilakukan oleh dukun. Persalinan lama (partus kasep) adalah persalinan yang berjalan lebih dari 24 jam untuk primigravida dan atau 18 jam bagi multigravida. Persalinan kasep (partus kasep) merupakan partus lama yang disertai komplikasi ibu maupun janin (Manuaba, 2010). Data yang diperoleh dari Rumah Sakit Umum Daerah (RSUD) Ade Mohammad Djoen Sintang selama 3 tahun terakhir terjadi peningkatan kasus partus lama. Pada tahun 2017 sebanya 41 kasus dan pada tahun 2018 meningkat menjad 65 kasus. Dan pada than 2019 sebnyak 47 kasus. Penyebab partus lama di Rumah Sakit Umum Daerah (RSUD) Ade Mohammad Djoen Sintang diantaranya adalah inersia uteri, incoordinate uterin action, CPD (Cephalopelvik), kelainan letak janin (letak lintang dan sungsang) (Profil RSUD Ade Mohammad Djoen, 2019). Partus lama dapat mengakibatkan trauma, asidosis, kerusakan hipoksik, infeksi, peningkatan mortalitas serta morbiditas pada bayi. Selain pada bayi partus lama juga mengakibatkan ibu mengalami penurunan semangat, kelelahan, dehidrasi, asidosis, infeksi, resiko rupture uterus, dan perlunya intervensi bedah meningkatkan mortalitas dan morbiditas
(Maryunani A. \& Sari, Puspita, E., 2013).

\section{METODE}

Desain pada penelitian ini menggunakan desain penelitian deskriptif kuantitatif dengan pendekatan retrospektif. Penelitian deskriptif adalah suatu metode penelitian yang dilakukan dengan tujuan utama membuat gambaran atau deskriptif suatu keadaan atau area populasi tertentu yang bersifat faktual secara objektif. Pendekatan kuantitatif adalah data yang berhubungan dengan angka-angka yang diperoleh dari hasil pengukuran (Notoatmodjo, 2010). Pendekatan studi retrospektif yaitu jika meneliti peristiwa kebelakang menggunakan data sekunder (Chandra, 2008). Pada penelitian ini, peneliti ingin mengetahui Bagaimana Analisis hubungan ketuban pecah dini (KPD) dan paritas dengan partus lama. Desain pada penelitian ini menggunakan desain penelitian deskriptif kuantitatif dengan pendekatan retrospektif. Populasi dalam penelitian ini adalah seluruh ibu yang melahirkan di RSUD Ade Muhammad Djoen Sintang Tahun 2019 yang berjumlah 1.383 orang, jumlah sampel yaitu sebanyak 310 . Teknik pengambilan sampel yang digunakan dalam penelitian ini adalah simple random sampling. Sampel penelitian menggunakan Lembar Ceklist. Analisis data menggunakan analisis Univariat dan bivariat.

\section{HASIL}

Tabel 1. Karakteristik Responden

\begin{tabular}{lcc}
\multicolumn{1}{c}{ Variabel } & Jumlah & Persentase \\
\hline KPD & & \\
Ya & 144 & $46.5 \%$ \\
Tidak & 166 & $53.5 \%$
\end{tabular}

Paritas 


\begin{tabular}{|c|c|c|}
\hline Berisiko & 144 & $46.5 \%$ \\
\hline Tidak berisiko & 166 & $53.5 \%$ \\
\hline $\begin{array}{l}\text { Partus lama } \\
Y a\end{array}$ & & \\
\hline $\begin{array}{l}\text { Ya } \\
\text { Tidak }\end{array}$ & 136 & $56.1 \%$ \\
\hline Tidak & 174 & $43.9 \%$ \\
\hline
\end{tabular}

dari ibu bersalin dengan KPD dan memiliki paritas berisiko, yaitu 144 responden $(46.5 \%)$, dan $56.1 \%$ ibu bersalin melahirkan dengan partus lama.

Tabel 2. Hubungan KPD dan Paritas dengan Partus Lama

\begin{tabular}{|c|c|c|c|c|c|c|}
\hline \multirow[t]{2}{*}{ Variabel } & \multicolumn{4}{|c|}{ Partus Lama } & \multirow{2}{*}{$\begin{array}{c}\text { OR } \\
(95 \% \mathrm{CI})\end{array}$} & \multirow[t]{2}{*}{ p-value } \\
\hline & Ya & $\%$ & Tidak & $\%$ & & \\
\hline $\begin{array}{l}\text { KPD } \\
\text { Ya } \\
\text { Tidak }\end{array}$ & $\begin{array}{l}59 \\
77\end{array}$ & $\begin{array}{c}41 \\
46.4\end{array}$ & $\begin{array}{l}85 \\
89 \\
\end{array}$ & $\begin{array}{c}59 \\
35.6\end{array}$ & $\begin{array}{c}2.8 \\
(2.5-3.3)\end{array}$ & 0.004 \\
\hline $\begin{array}{l}\text { Paritas } \\
\text { Beresiko } \\
\text { Tidak beresiko }\end{array}$ & $\begin{array}{l}61 \\
75\end{array}$ & $\begin{array}{l}42.4 \\
45.2\end{array}$ & $\begin{array}{l}83 \\
91\end{array}$ & $\begin{array}{l}57.6 \\
54.8\end{array}$ & $\begin{array}{c}2.9 \\
(3.6-5.2)\end{array}$ & 0.004 \\
\hline
\end{tabular}

Hasil analisis yang tertuang pada tabel 2 menunjukkan bahwa adanya hubungan yang signifikan, yaitu variabel KPD $(P$ value 0.004$)$ dan variabel paritas $(P$ value 0.004). Hal ini berarti ibu yang mngalami KPD mempunyai peluang 2.8 kali lebih besar untuk mengalami partus lama dibandingkan dengan ibu yang tidak mengalami partus lama. Dan ibu yang memunyai paritas berisiko mempunyai peluang 2.9 kali lebih besar untuk mengalami partus lama dibandingkan dengan ibu yang tidak mengalami partus lama.

\section{PEMBAHASAN}

Dapat dilihat sebagian dari ibu bersalin dengan KPD yaitu 144 responden $(46,5 \%)$, sedangkan sebagian ibu bersalin yang tidak mengalami KPD yaitu 166 responden $(53,5 \%)$. Berdasarkan tabel 4.2 dari 310 responden dapat dilihat sebagian dari ibu bersalin dengan partus lama yaitu 136 responden $(56,1 \%)$, sedangkan sebagian ibu bersalin melahirkan tidak partus lama yaitu 176 responden (43,9\%). Berdasarkan tabel 4.4 dari 310 responden dapat dilihat menunjukkan bahwa adanya hubungan yang signifikan yaitu variabel paritas $\mathrm{OR}=2,891 ; 95 \%$
$\mathrm{CI}=3,568-5,237 ; \mathrm{P}=0.004)$. Hal ini berarti ibu yang mngalami KPD mempunyai peluang 2,802 kali lebih besar untuk mengalami partus lama dibandingkan dengan ibu yang tidak mengalami partus lama.

Menurut penelitian Utomo (2013) Riwayat kejadian KPD sebelumnya menunjukkan bahwa wanita yang telah melahirkan beberapa kali dan mengalami KPD pada kehamilan berikutnya. Keadaan yang dapat menganggu kesehatan ibu dan janin dalam kandungan juga dapat meningkatkan resiko kelahiran dengan ketuban pecah dini. Preeklampsia/ eklampsia pada ibu hamil mempunyai pengatuh langsung terhadap kualitas dan keadaan janin karena terjadi penurunan darah ke plasenta yang mengakibatkan janin berkurang nutrisi.

Menurut (Dutton, 2011) faktor penyebab ketuban pecah dini adalah riwayat KPD sebelumnya, serviks inkompoten, gemeli, paritas, anemia, sosial ekonomi (pekerjaan), hidramnion, kelainan letak janin, usia dan merokok. Hasil penelitian ini berbeda dengan penelitian yang dilakukan oleh Susilowati dengan 
judul "Gambaran Karakteristik Ibu Bersalin dengan Ketuban Pecah Dini di Rumah Sakit Panti Wilasa Citarum Seamarang Tahun 2009" dimana hasil penelitian menunjukkan bahwa karakteristik ibu bersalin dengan Ketuban Pecah Dini meliputi 20-35 tahun, primigravida, usia kehamilan 37-42 minggu, multipara dan bersalin dengan sectio caesarea. Hal ini karena disebabkan ketegangan rahim meningkat, sehingga membuat selaput ketuban pecah sebelum waktunya (Manuaba, 2010). Sehingga ketuban bagian terendah langsung menerima tekanan intra uteri yang dominan, seperti sungsang dan lintang, sehingga tidak ada bagian yang terendah menutupi pintu atas panggul (PAP) yang dapat menghalangi tekanan terhadap membrane bagian bawah.

Berdasarkan tabel 4.2 dari 310 responden dapat dilihat sebagian dari ibu bersalin Paritas tidak beresiko yaitu 166 responden $(53,5 \%)$, sedangkan sebagian ibu bersalin melahirkan Paritas beresiko yaitu 144 responden (46,5\%). Berdasarkan tabel 4.2 dari 310 responden dapat dilihat sebagian dari ibu bersalin dengan partus lama yaitu 136 responden (56,1\%), sedangkan sebagian ibu bersalin melahirkan tidak partus lama yaitu 176 responden (43,9\%). Berdasarkan tabel 4.4 dari 310 responden dapat dilihat menunjukkan bahwa adanya hubungan yang signifikan yaitu variabel paritas $\mathrm{OR}=2,891 ; 95 \%$ $\mathrm{CI}=3,568-5,237 ; \mathrm{P}=0.004)$. Hal ini berarti ibu yang mempunyai paritas berisiko mempunyai peluang 2,891 kali lebih besar untuk mengalami partus lama dibandingkan dengan ibu yang tidak mengalami partus lama.
Multigravida atau paritas tinggi merupakan salah satu dari penyebab terjadinya kasus ketuban pecah sebelum waktunya. Paritas 2-3 dan paritas paling aman ditinjau dari sudut kematian. Paritas 1 dan paritas tinggi (lebih dari 3) mempunyai angka kematian maternal lebih tinggi, risiko pada paritas 1 dapat ditangani dengan asuhan obstetrik lebih baik, sedangkan risiko pada paritas tinggi dapat dikurangi/dicegah dengan keluarga berencana. Ibu yang telah melahirkan beberapa kali lebih berisiko mengalami KPD, oleh karena vaskularirasi pada uterus mengalami gangguan dan mengakibatkan jaringan ikat selaput ketuban mudah rapuh dan akhirnya akan pecah spontan. (Wiknjosastro, 2011).

Mengapa yang tidak berisiko bisa mengalami ketuban pecah dini dikarenakan terkena oleh faktor yang lainnya seperti yang ada di teori Dutton (2011) menyatakan bahwa faktor penyebab ketuban pecah dini yaitu Riwayat KPD, servik Inkompoten, gemeli, paritas, anemia, sosial ekonomi (pekerjaan), hidramnion, kelainan letak janin, usia dan merokok.

\section{KESIMPULAN}

Adanya hubungan yang signifikan variabel KPD dan paritas terhadap partus lama ibu melahirkan. Ibu yang mengalami KPD mempunyai peluang 2.8 kali lebih besar untuk mengalami partus lama dibandingkan dengan ibu yang tidak mengalami partus lama. Ibu yang mempunyai paritas berisiko mempunyai peluang 2.9 kali lebih besar untuk mengalami partus lama dibandingkan dengan ibu yang tidak mengalami partus lama.

\section{SARAN}


Bagi Rumah Sakit Disarankan Pelayanan kesehatan di Rumah Sakit sudah cukup baik, namun diharapkan kepada petugas kesehatan tetap mempertahankan pelayanan yang sudah ada dan bahkan lebih ditingkatkan lagi. Adapun pelayanan di Rumah Sakit yang harus ditingkatkan adalah pemberian pendidikan kesehatan kepada ibu bersalin tentang partus lama dan akibat dari partus lama pada bayi dan ibu, serta informed consent kepada ibu bersalin tentang tindakan SC (Section Caesarea) apabila terjadi partus lama. Tindakan ini dilakukan karena setiap ibu yang bersalin beresiko mengalami partus lama.

\section{DAFTAR PUSTAKA}

Achadiat. (2011). Obstetri dan Ginekologi. Jakarta: KDT

Maryunani, A., \& Puspita, E. (2013). Asuhan Kegawatdaruratan Maternal dan Neonatal. Jakarta: TIM.

Baety, A. N. (2011). Biologi Reproduksi kehamilan dan persalinan. Yogyakarta: Graha Ilmu.

Chandra, Budiman. (2011). Metodelogi Penelitian Kesehatan. Jakarta: EGC

Kemenkes, R. I. (2015). Profil kesehatan indonesia. Jakarta: Kemenkes RI.. Tersedia: www.depkes.go.id (diakses pada 19 Maret 2020, Pukul : 10:46 WIB)

Dinkes. (2016). Profil Kesehatan Sintang Tahun 2016. Sintang

Dutton, L. A., Densmore, J. E., \& Turner, M. B. (2011). Rujukan cepat kebidanan. Jakarta: EGC.

Fadlun, F. A.(2011). Asuhan kebidanan patologis. Jakarta: Salemba Medika.

Frelestanty, E., \& Haryanti, Y. (2020). ANALISIS PENYEBAB TERJADINYA KETUBAN PECAH DINI PADA IBU BERSALIN. JURNAL KEBIDANAN, 9(2).

Icesmi, S. K., \& Margareth, Z. H. (2013). Kehamilan, Persalinan, dan Nifas. Yogyakarta: Nuha Medika.
Frelestanty, E., \& Haryanti, Y. (2020). ANALISIS PENYEBAB TERJADINYA KETUBAN PECAH DINI PADA IBU BERSALIN. JURNAL KEBIDANAN, 9(2).

Kemenkes. 2016. Direktorat Kesehatan Keluarga. Jakarta

Kusmiyati, Y., \& Wahyuningsih, H. P. (2013). Asuhan ibu hamil. Fitramaya. Yogyakarta. Hal, 102.

Lauren,

Cathy. 2013. Ketuban Pecah Dini. Jakarta.

Lisnawati, L. (2013). Asuhan Kebidanan Terkini Kegawatdaruratan Maternal dan Neonatal. Jakarta: Trans Info Media.

Warnaliza, D., \& Nugroho, T. (2014). Buku Ajar Askeb 1 Kehamilan. Yogyakarta: Nuha Medika.

Sari, A. N. (2016). GAMBARAN FAKTOR PENYEBAB KEJADIAN KETUBAN PECAH DINI (KPD) PADA IBU BERSALIN DI RSUD YOGYAKARTA TAHUN 2015.

Obstetric. (2016). obstetric revised edition.Jakarta : Medika

Pratiwi, D. E., \& Muhartati, M. (2017). HUBUNGAN ANEMIA DENGAN KEJADIAN KETUBAN PECAH DINI PADA IBU BERSALIN DI RSUD MUNTILAN.

Pupista, Eka. (2014). Asuhan Persalianan Normal.Jakarta

Rohani, D. (2014). Asuhan Kebidanan Pada masa Persalinan. Salemba Medika: Jakarta.

Abil, R. (2015). Buku Ajar Analisis Data Penelitian Kesehatan Dengan SPSS.

Prawirohardjo, S. (2012). Buku acuan nasional pelayanan kesehatan maternal dan neonatal. Jakarta: PT Bina Pustaka Sarwono Prawirohardjo.

Prawirohardjo, S. (2014). Ilmu Kebidanan Sarwono Prawirohardjo. Jakarta: PT Bina Pustaka Sarwono Prawiroharjo.

Sugiyono. (2011). Metode Penelitian Administasi. Bandung : Alvabe

Sulistyaningsih. (2011). Metode Penelitian Kuantitatif dan Kualitatif. Yogyakarta: Graha IImu

Susilowati, E. (2010). Gambaran Karakteristik Ibu Bersalin dengan 
Ketuban Pecah Dini di Rumah Sakit Panti Wilasa Citarum Semarang Tahun 2009. Jurnal Kebidanan Pantiwilasa, 1(1).

Wayan, Gede. (2014). Junal Penelitian Analisis Sosial Ekonomi.Serang 